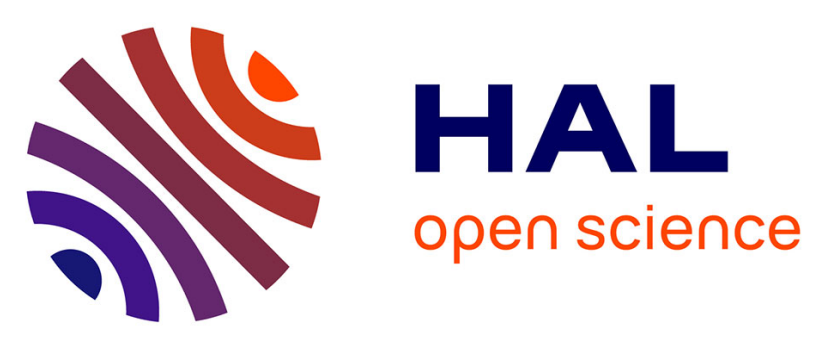

\title{
La céramique gallo-romaine du Ier siècle dans le sud de l'Atrébatie
}

\author{
Marie Tuffreau-Libre, Alain Jacques
}

\section{To cite this version:}

Marie Tuffreau-Libre, Alain Jacques. La céramique gallo-romaine du Ier siècle dans le sud de l'Atrébatie. Gallia - Fouilles et monuments archéologiques en France métropolitaine, 1985, 43 (1), pp.127-145. 10.3406/galia.1985.2823 . hal-01940085

\section{HAL Id: hal-01940085 \\ https://hal.science/hal-01940085}

Submitted on 27 Feb 2020

HAL is a multi-disciplinary open access archive for the deposit and dissemination of scientific research documents, whether they are published or not. The documents may come from teaching and research institutions in France or abroad, or from public or private research centers.
L'archive ouverte pluridisciplinaire HAL, est destinée au dépôt et à la diffusion de documents scientifiques de niveau recherche, publiés ou non, émanant des établissements d'enseignement et de recherche français ou étrangers, des laboratoires publics ou privés.

\section{(ㅇ)(1) $\$$}

Distributed under a Creative Commons Attribution - NonCommercial - NoDerivatives| 4.0 


\title{
LA CÉRAMIQUE GALLO-ROMAINE DU jer SIÈCLE DANS LE SUD DE L'ATRÉBATIE
}

\author{
par Marie TUFFREAU-LIBRE et Alain JACQUES
}

L'étude suivante réunit quelques sites caractéristiques de l'Atrébatie du Sud. La plupart sont inédits sauf ceux de Vimy ${ }^{1}$, Noyelles-Godault ${ }^{2}$ et de Hamblain-les-Prés ${ }^{3}$ (fig. 1). Il s'agit de nécropoles (Vimy, Vaulx-Vraucourt', Novelles-Godault), d'habitats de campagne (Hamblain-les-Prés, Rémy, Foncquevillers), enfin d'une ville romaine, Arras (Nemetacum) $)^{5}$ (fig. 2), en résumé donc d'une ville romaine et de sa région. Il nous a en effet paru intéressant de pouvoir étudier un secteur à la fois suffisamment important pour tirer des conclusions valables, mais assez limité pour éviter la confusion. Ces fouilles sont récentes et ont permis pour la plupart une étude exhaustive et des comptages du mobilier et donc des comparaisons statistiques. L'intérêt est ici de considérer des objets provenant de structures différentes mais contemporaines. Nous avons ainsi pu mettre en évidence deux faits : tout d'abord l'émergence tardive d'une céramique véritablement gallo-romaine, c'est-à-dire mixte, à la fin du ${ }^{\mathrm{er}}$ s., ensuite la différence d'évolution du mobilier dans les villes, les campagnes et les nécropoles.

Les objets utilisés pour cette étude sont d'abord décrits, accompagnés chaque fois d'une notice résumant brièvement chaque site envisagé. Nous avons limité les comparaisons typologiques aux exemples régionaux et significatifs. Leur abondance excessive est plus nuisible qu'utile et finit souvent par couvrir l'essentiel. L'étude synthétique du mobilier et les conclusions qu'elle permet viennent ensuite.

I E. Moxchy, Sépullures du I er siècle ap. J.-C. à Vimy, 1977, 71 p., 30 fig.

2 J. M. Bastien el P. Demolon, Villa el cimetière dil Ier siècle ap. J.-C. à Noyelles-Godault (Pas-de-Calais), dans Septentrion, 5, 1975, 35 p., 23 fig.

3 A. Jacques et Marie Tuffreau-Libre, La villa gallo-romaine d'llamblain-les-Près. Les étals du Ier siècle, dans Revue du Nord LXVI, 1984, pp. 181-205, 14 fig.

4 Nous remercions M. E. Fontaine, qui nous a permis d'utiliser ses dessins inédits (fig. 7), qui serviront dans une publication à paraître sur la nécropole gallo-romaine de Vaulx-Vraucourt.

5 Les fouilles récentes de la ville romaine d'Arras ont apporté de nombreux renseignements et un matériel abondant pour les périodes tardives (IV ${ }^{\mathrm{e}} \mathrm{s}$.) mais aussi pour le Haut-Empire. 


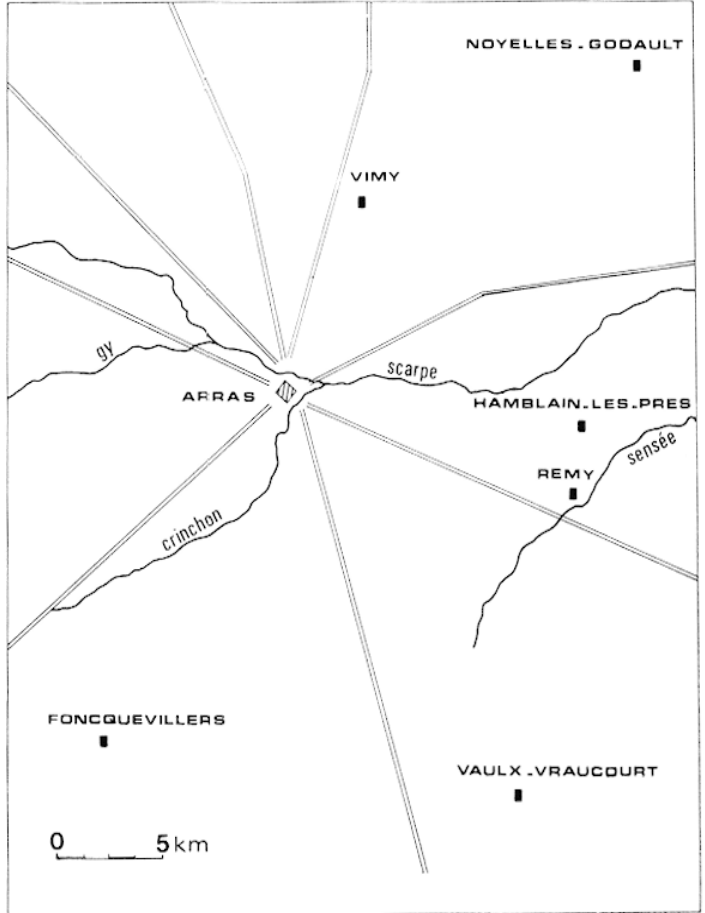

1 Arras el sa région, carte des sites envisagés.
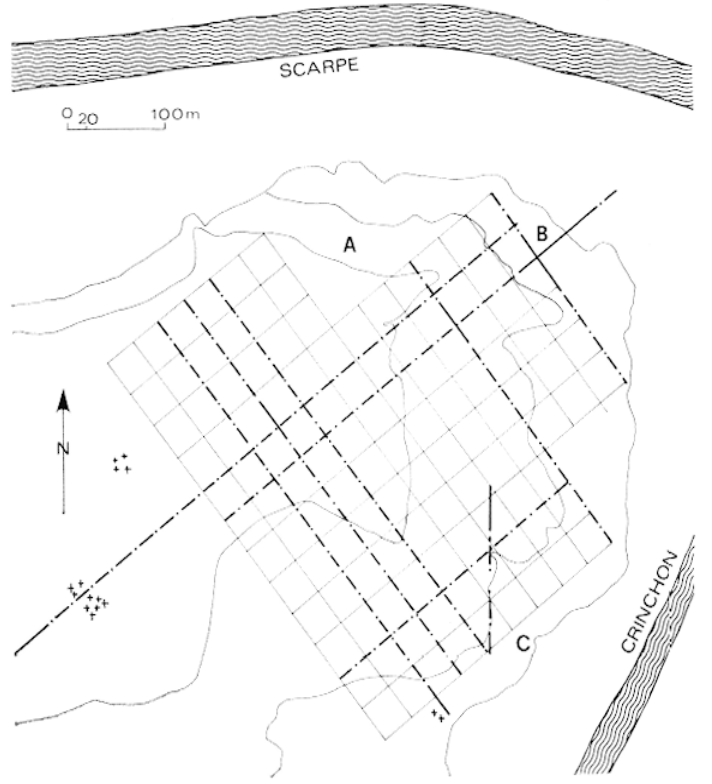

2 Plan d'Arras antique : A : décharge antique du Baudimont, B : rue N.-D. de Lorette, C : clinique Bon Secours. Les croix indiquent les nécropoles; les tiretés, les voies romaines reconnues; les traits pleins, les voies supposées.

\section{DESCRIPTION DES CÉRAMIQUES.}

Noyelles-Godault, tombe 4 (fig. 3). - Ce site comprend une villa ayant livré très peu de mobilier et une nécropole datée par les auteurs de la période Auguste-Claude.

$\mathbf{n}^{0} 1$ : assiette tournée en terra nigra ; lèvre soulignée par une petite rainure, rebord oblique ; fond plat ; pied à peine marqué ; couleur gris foncé (Munsell Soil Color Charts 7,5 YR N 3/, 2,5/); pâte gris clair à dégraissant sableux, mal cuite.

Type III b des assiettes carénées ${ }^{6}$, connu à Nimègue $^{7}$, proche de Camulodunum $2 \mathrm{~B} 2 \mathrm{C}$ (période I-IV) ${ }^{8}$.

no 2 : vase tourné; lèvre arrondie, éversée; col concave; épaule haute formant méplat; pied annelé ; couleur grise (10 YR 4/2); pâte à cour brun rouge, à dégraissant sableux, cuisson moyenne.

Type II a des vases ovoïdes.

no 3 : bol tourné ; lèvre arrondie, éversée ; col tronconique mouluré ; panse carénée; pied

6 Marie Tufreat-Libre, La céramique commune gallo-romaine dans le Nord de la France (Nord, Pas-de-Calais). Presses Universitaires de Lille, 1980, 286 p., 123 fig.

7 W. Vanvinckenroye, Gallo-romeins aardewek van Tongeren, Tongres 1967, 69 p., 26 pl. h.-t.

8 C. F. C. Hawnes et M. R. HuLl, Camulodunum, first report on the excavations al Colchester, dans Reports of the Research Committee of the Society of Antiquaries of London, 1974, 361 p., 66 fig. 112 pl. h.-t. 
CÉRAMIQUE GALLO-ROMAINE DE L'ATRÉBATIE

129
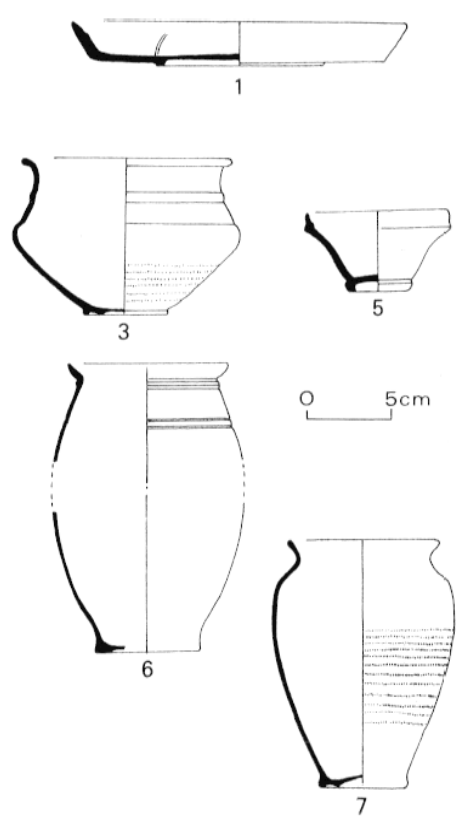

3 Mobilier de la tombe no 4 de Noyelles-Godault.

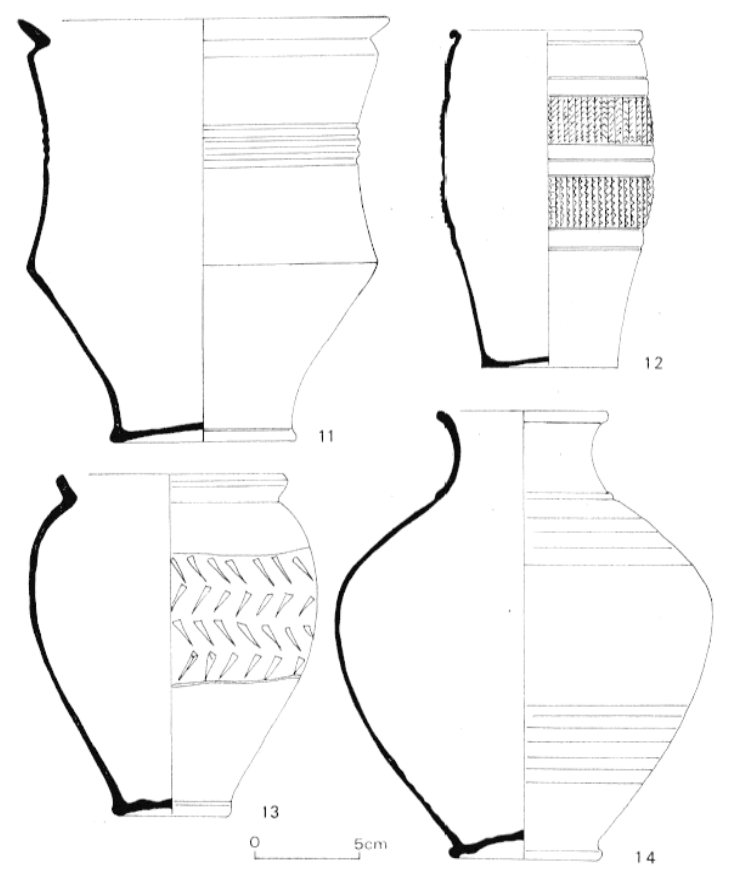

5 Mobilier de la tombe $n^{\circ} 8$ de Vimy nos 11 à 14 .

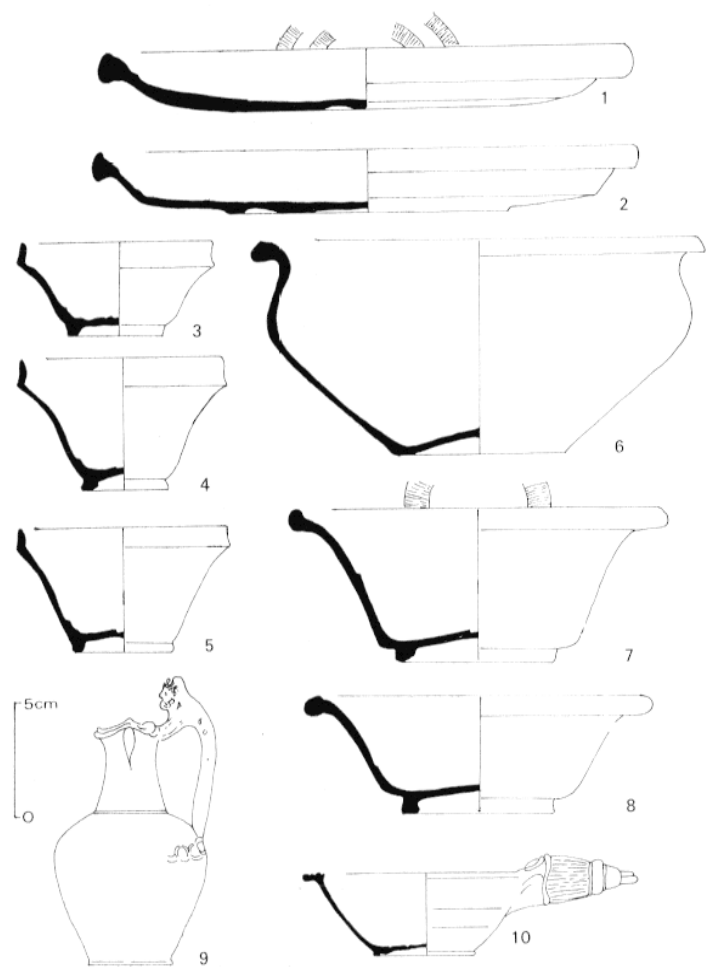

4 Mobilier de la tombe no 8 de Vimy $n^{o s} 1$ à 10.

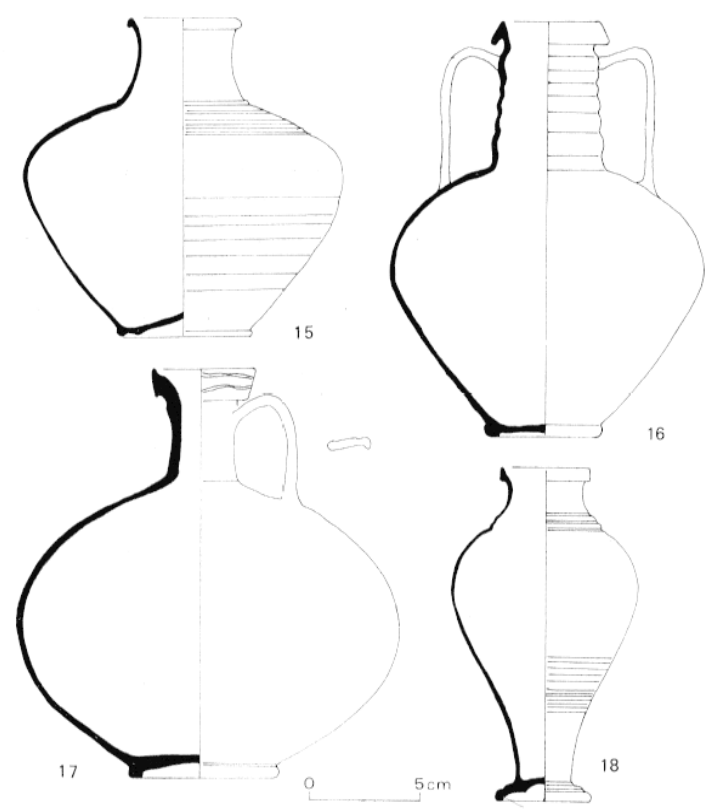

6 Mobilier de la tombe no 8 de Vimy. nos 15 à 18. 
arrondi ; fond creusé, marqué d'un anneau ; couleur grise (10YR 4/1); pâte grise, à dégraissant sableux, bien cuite.

Type XV b des bols carénés, forme apparenlée à Camulodunum 209 (période I).

no 4 : vase tourné en terra rubra; lèvre oblique éversée ; col droit, mouluré ; panse carénée ; pied arrondi, cannelé ; fond légèrement concave ; couleur orange (5 YR $4 / 4,2,5$ YR 5/6, 5/8); pâte orange ; cuisson moyenne.

Type II d des vases carénés, Holwerda 9 a (Auguste-Tibère) ${ }^{9}$.

$\mathbf{n}^{0} \mathbf{5}$ : bol à enduit rouge; lèvre verlicale ; panse oblique ; pied arrondi ; fond creusé ; couleur orange ; engobe rouge à l'intérieur et sur l'extérieur de la lèvre $(2,5$ YR $5 / 6)$; pâte orange à dégraissant sableux, bien cuite.

Type III a des bols à panse oblique, connu en Angleterre à Colchester (type 56 Auguste à Claude).

no $^{0}$ : vase tourné en terra rubra ; lèvre éversée, suivie d'un bourrelet ; panse ovoïde, moulurée ; pied oblique ; fond creusé ; couleur brun orange $(7,5$ YR $5 / 4)$; pâte orange à fin dégraissant sableux, cuisson moyenne.

Type III a des vases ovoïdes.

$\mathrm{n}^{\circ} \mathrm{yy}$ : vase tourné ; lèvre ronde, éversée ; épaule haute en méplat; pied oblique, arrondi à la base ; fond creusé, marqué d'un anneau saillant ; couleur grise (10 YR 4/2); pâte grise à dégraissant sableux; cuisson moyenne.

Vimy, tombe 8 (fig. $4,5,6$ ). - Cette nécropole n'a livré que dix tombes fouillées en sauvetage et datées de la période Auguste-Claude.

$\mathbf{n}^{0} 1$ : assiette tournée à enduit rouge ; lèvre en bandeau; corps oblique ; fond creusé ; enduit rouge à l'intérieur et sur le rebord de la lèvre (l'auteur ne donne ni la couleur en code Munsell, ni d'indication sur la pâte).

Type Gose 291 (Augustéen) ${ }^{10}$.

no 2 : assiette tournée en terra nigra ; lèvre en bandeau ; paŕie supérieure oblique; partie inférieure carénée ; fond creusé ; couleur noire.

Type Gose 294 (époque claudienne).

$\mathbf{n}^{0} 3$ : bol tourné en terra nigra ; lèvre verticale; panse oblique ; pied oblique; fond creusé ; couleur noire.

Type III a des bols à panse oblique, connu à Colchester $(56 \mathrm{c})$.

$\mathbf{n}^{\circ} 4$ : bol tourné à enduit rouge, identique au précédent.

$\mathbf{n}^{0} \mathbf{5}$ : bol tourné en terra nigra, identique aux deux précédents.

$\mathbf{n}^{\circ} 6$ : bol tourné ; lèvre épaisse, allongée ; col concave ; panse carénée ; fond concave ; couleur noire.

Type XVI c des bols carénés, connu à Noyelles Godault, à $\Lambda$ rras ${ }^{11}$.

9 J. H. Holwerd, De Belgische waar in Nijmegen, Beschrijbing van hel museum G. M. Kam te Nijmegen, 1941, 152 p., 21 pl. h.-t.

10 E. Gose, Gefasslypen der römischen Keramili im Rheinland, Rheinisches landesmuseum, Bonn, 1950, 47 p., 61 pl. h.-t.

11 Marie Turrneau-Libre, Ia céramique commune gallo-romaine du sile de Baudimont à Arras, dans Bullelin de la Commission Départementale des Monuments Historiques du Pas-de-Calais, X, 1978, pp. 177-206, 16 fig. 
$\mathrm{n}^{0} \mathbf{y}$ : bol tourné en terra nigra ; lèvre ronde, saillant vers l'intérieur ; panse oblique ; corniche intérieure; pied oblique; fond concave.

Type IV a des bols à panse oblique, connu à Noyelles-Godault (Tibère), type Gose 305 (Auguste'Tibère), Colchester 53 b (période I-III).

$\mathbf{n}^{0} 8$ : bol tourné à enduit rouge, proche du précédent; enduit rouge à l'intérieur et sur la lèvre.

$\mathbf{n}^{0} 9$ : cruche tournée, dorée au mica ; bec tréflé ; col tronconique ; panse ronde ; pied renflé ; anse terminée par une tête d'homme barbu ; couleur orange, engobe dorée au mica.

Ces cruches sont notamment connues à Beugin et à Arras ${ }^{12}$. Il s'agit d'une imitation directe d'objets en bronze.

$\mathbf{n}^{0} 10$ : patère tournée dorée au mica; lèvre aplatie et moulurée; panse ronde ; oblique; fond concave, mouluré. Le manche est renflé, s'élargissant à l'extrémité, terminé par un anneau de suspension. Le manche est décoré de stries parallèles. La base du manche est ornée de trois dépressions ovalaires. L'intérieur de la patère est décoré de motifs circulaires.

Il s'agit d'une imitation d'objet en bronze, généralement associée à la cruche à bec tréflé précédente.

$\mathbf{n}^{0} 11$ : vase tourné en terra rubra; lèvre oblique, éversée; col concave, mouluré; panse carénée ; pied arrondi ; fond creusé, concave.

Type II d des vases carénés, connu à Noyelles-Godault.

$\mathrm{n}^{0} 12$ : vase tourné en terra rubra; lèvre arrondie, saillant vers l'intérieur; panse ovoïde, moulurée ; fond creusé. La panse est décorée à la roulette.

Type IV a des vases ovoïdes.

$n^{0} 13$ : vase tourné ; lèvre oblique, éversée ; panse ovoïde ; pied arrondi ; fond creusé ; couleur blanche. La panse est décorée d'aiguilles en relief.

Type connu à Nimègue (Auguste-Tibère), à Haltern ${ }^{13}$, type 86, à Colchester, en Rhénanie (Gose 337, époque de Tibère), à Sept-Saulx (Champagne, fin de l'époque tibérienne) ${ }^{14}$, à Hamblain-les-Prés (époque claudienne).

$n^{0} 14$ : bouteille tournée en terra nigra; lèvre ronde, fine, col concave terminé par une moulure ; panse ronde ; pied arrondi ; fond creusé ; couleur noire.

$\mathbf{n}^{0} 15$ : bouteille tournée en terra nigra ; lèvre ronde fine; col concave se terminant par une corniche ; panse très large ; petit pied arrondi ; fond creusé ; couleur noire.

$\mathbf{n}^{0} 16$ : cruche tournée; lèvre en crochet; col tronconique mouluré ; panse ronde, large ; pied arrondi ; fond creusé ; deux anses fines ; couleur blanche.

Type IV c des cruches à deux anses, connu à Noyelles-Godault (époque claudienne), en Angleterre à Colchester (163 a période I-IV).

12 Marie Tufrreau-Libre, La céramique dorée au mica dans le Nord de la France (Nord el Picardie), dans Helinium, XVIII, 1978, pp. 105-125, 13 fig.

13 B. Loeschicke, Keramische funde in Hallern, 1909, 324 p., 30 pl. h.-t.

14 Marie Tuffreau-Libre, L'industrie de la ceramique gallo-belge dans la vallee de la Vesle, dans Bulletin de la socièle archéologique champenoise, 1981, 2, pp. 81-94, 12 fig. 
$n^{\circ} 1^{1 \%}$ : cruche tournée ; lèvre oblique ; col légèrement concave ; panse ronde, très large ; pied arrondi ; fond concave, couleur blanche. La lèvre est ornée de sillons en spirales.

$n^{0} 18$ : bouteille tournée en terra nigra ; lèvre droite ; col concave ; panse ovoïde, moulurée ; pied à baluslre mouluré ; fond creusé orné d'un anneau ; couleur noire.

Type dérivé des formes à piédestal gauloises.

Vaulx-Vraucourt (fig. 7). - Ce cimetière gallo-romain a également été l'objet d'un sauvetage. Ses datations vont de la période augustéenne au dernier quart du I $^{\mathrm{er}} \mathrm{s}$., pour les tombes les plus récentes. Nous présentons ici quelques-unes des formes de cette nécropole inédite encore. Nous n'avons pas d'indications de couleur ni de pâte.

$\mathrm{n}^{0} 1$ : bol à lèvre anguleuse; panse ronde; fond plat.

Type traditionnel gaulois, connu à Villeneuve-Saint-Germain (début de l'époque augustéenne, ${ }^{15}$.

$\mathbf{n}^{0} 2$ : bol à lèvre arrondie, éversée ; col concave, mouluré ; panse carénée ; petit pied arrondi ; fond creusé.

Type XVI d des bols carénés.

$n^{0} 3$ : vase à lèvre fine, arrondie ; col concave ; panse ovoïde ; pied à balustre, ćtroit, s'évasant largement à la base ; fond plat ; décor lissé sur la panse.

no 4 : bouteille; lèvre éversée, anguleuse; col long, concave, terminé par une moulure; panse large ; pied oblique, mouluré ; fond concave ; décor lissé quadrillé.

$\mathbf{n}^{\circ} \mathbf{5}$ : bouteille à lèvre fine, ronde, fortement éversée ; col concave, se terminant par trois moulures ; panse ronde; pied très petit; fond creusè marqué d'un anneau saillant; décor lissé parallèle.

$\mathrm{n}^{\circ} 6$ : assiette gallo-belge ; lèvre épaisse ; panse ronde ; fond creusé ; pied droit. Type connu à Nimègue (81 a) en Rhénanie (Gose 288, Caligula), en Angleterre à Colchester.

$\mathrm{n}^{0}$ y : assiette à lèvre fine, moulurée; col concave; panse anguleuse; pied oblique, assez haut ; fond concave.

$n^{\circ} 8$ : bol à lèvre arrondie, rentrante, prolongée par une panse ronde, ornée d'une collerette; pied oblique, fond creusé.

Type I a des bols à collerette, connu en terra nigra à Noyelles-Godault (période claudienne). Il s'agit d'une imitation de forme sigillée (Drag. 24/25). Il existe en Belgique, en Angleterre à Colchester (type $58 \mathrm{~A}$, période III-VI), en Rhénanie à Straubing (période flavienne, début du II ${ }^{\mathrm{e}} \mathrm{s}$. ${ }^{16}$.

no 9 : vase à lèvre oblique; panse ovoïde, moulurée; pied oblique, fond creusé.

$\mathrm{n}^{0} 10$ : vase à lèvre fine, prolongée par un col concave, terminé par une moulure; panse carénée ; pied oblique ; fond creusé.

Des types proches sont connus à Arras.

$15 \mathrm{~J}$. I) archéologique de Picardie, 1982, pp. 213-264, 51 fig.

16 N. WALKE, Das römische Donaukastelle Straubing-Sorviodorum, dans Limesforschung Band, 3, 1965, 176 p., 18 fig., 152 pl. h.-t. 

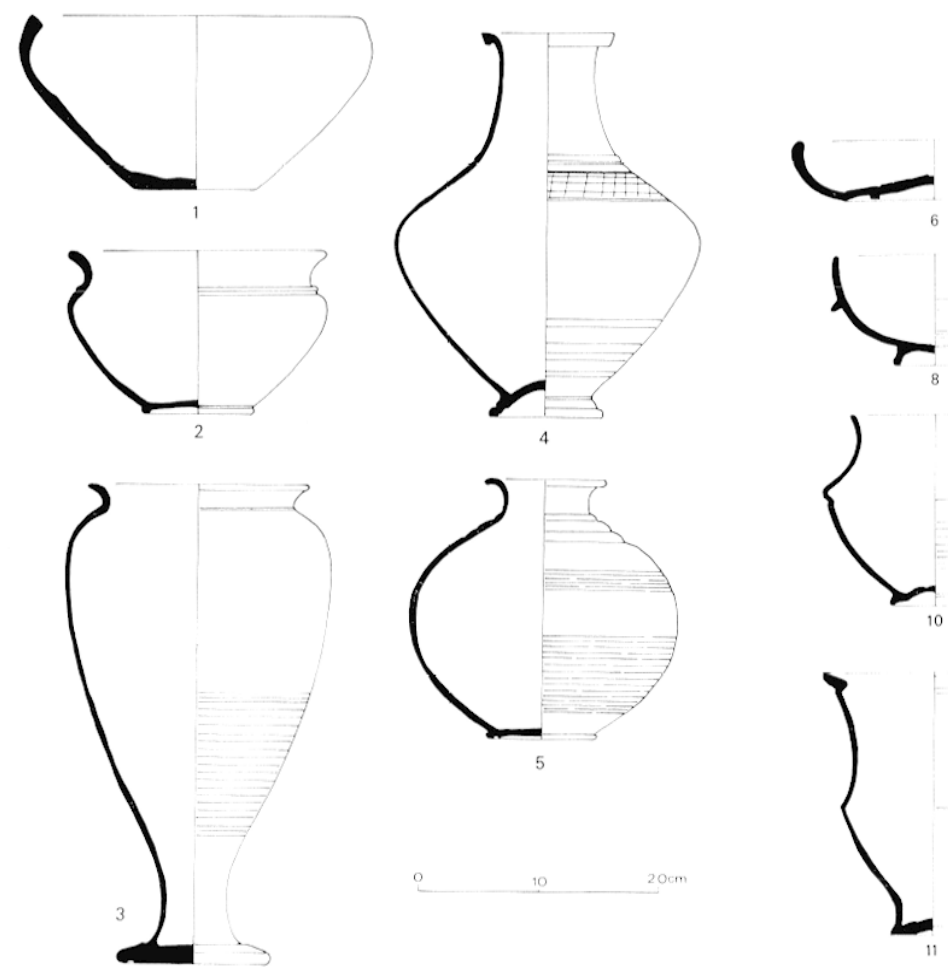

7 Exemples de céramiques connues à Vaulx-Vraucourl, dessins de E. liontaine.

no 11 : vase à lèvre longue, oblique, fortement éversée ; col concave. long ; panse carénée ; pied oblique ; fond légèrement creusé.

Type proche de ceux connus à Vimy.

$\mathbf{n}^{0} 12$ : vase à lèvre épaisse ; col tronconique ; panse ronde ; pied petit, fond concave. Type II a des vases tronconiques, caractéristique du Nord de la France ( ${ }^{\mathrm{er}} \mathrm{au}_{\mathrm{Iv}}^{\mathrm{e}} \mathrm{s}$.).

no 13 : cruche à lèvre cannelée; col concave ; panse ovoïde ; pied oblique ; fond creusé ; anse à une cannelure.

Les cruches à lèvre cannelée de ce type apparaissent dans le Nord dans la deuxième moitié du $\mathrm{I}^{\mathrm{er}} \mathrm{s}$.

Rémy (fig. 8). - Cé site fouillé en 1979 a permis de mettre en évidence des fossés et un collecteur remplis de débris de démolition provenant d'un habitat situé à proximité. L'ensemble du mobilier date de la période Auguste-Tibère.

$\mathbf{n}^{\circ} 1$ : bol non tourné; lèvre ronde ; col concave ; panse carénée couleur noire 7,5 YR $\times 3 /$, $6 / 2)$; intérieur beige ; pâte beige à dégraissant sableux bien cuite.

Type VIII a des bols carénés, de tradition gauloise.

$\mathrm{n}^{0} 2$ : bol tourné; lèvre oblique, s'affinant à l'extrémité; panse ronde; couleur noire (7,5 YR N 3/) ; pâte noire à dẻgraissant sableux, bien cuite.

Type VI a des bols à panse ronde, connu à Noyelles-Godault (Auguste-Tibère). 
no 3 : vase tourné; lèvre oblique, arrondie à la base; col concave; panse ronde; couleur grise (7,5 YR N 3/).

Type VI b des vases à panse ronde, connu à Noyelles-Godault (Auguste-Tibère).

no 4 : vase tourné ; lèvre plate, droite ; panse aplatie; couleur orange (5 YR 6/6); pâte fine, orange, à dégraissant sableux, bien cuite. La panse est percée d'un trou circulaire.
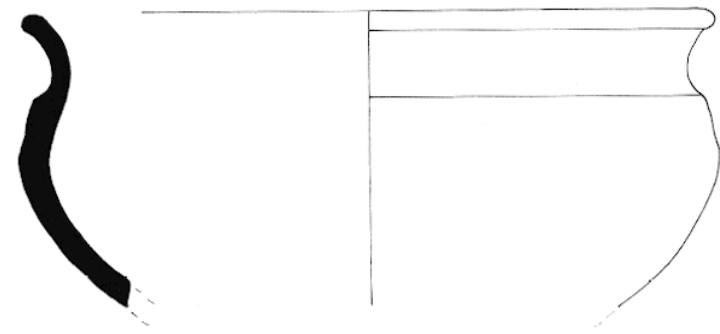

1
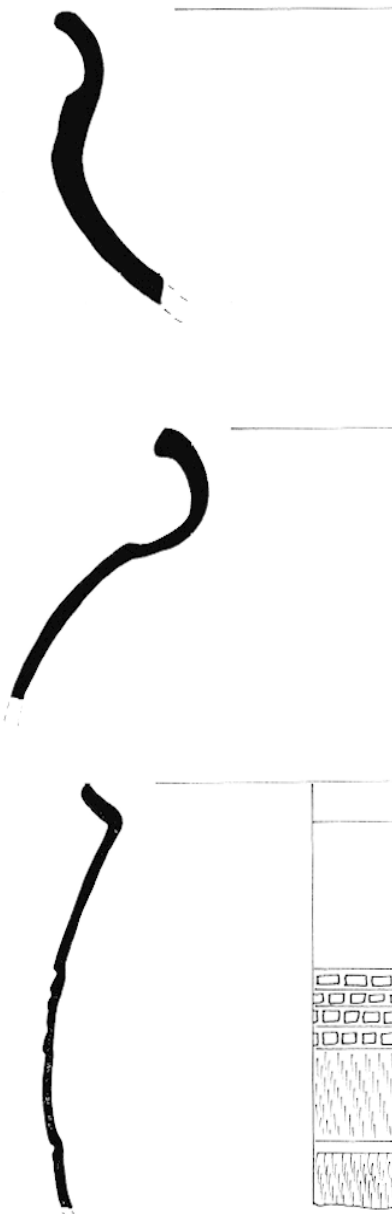
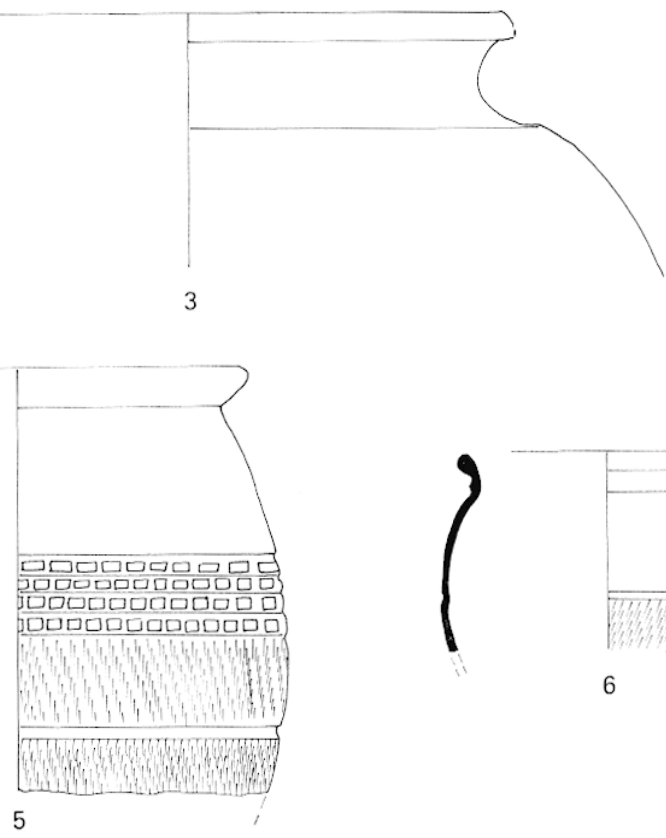

8 Mobilier de la fouille de Remy.

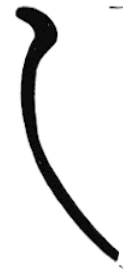

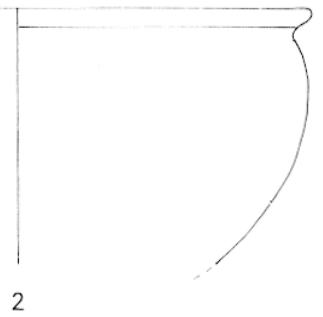

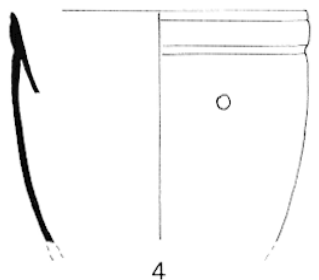

4
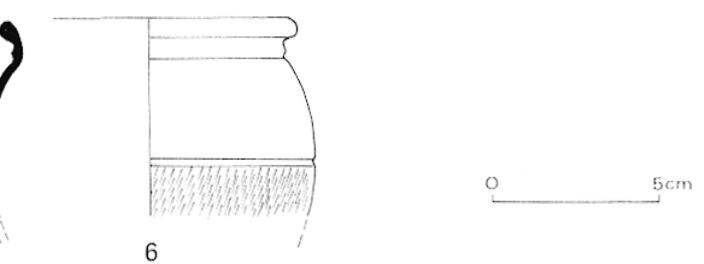

no 5 : vase tourné ; lèvre oblique ; panse ovoïde moulurée ; couleur blanche $(7,5$ YR 7/2,6/2); pâte blanche à dégraissant sableux, bien cuite. La panse est décorée de guillochis et de rectangles réalisés à la roulette.

Type IV a des vases ovoïdes.

no 6 : vase tourné à enduit rouge ; lèvre ronde, suivie d'une corniche ; panse ovoïde, moulurée ; couleur beige ; enduit rouge $(10 \mathrm{~K} 5 / 6)$ pâte beige, à dégraissant sableux, bien cuite. La panse est décorée de guillochis. 
Hamblain-les-Prés (fig. 9). - Cette villa romaine, succédant à une occupation gauloise comprend plusieurs états puisque l'abandon définitif se situe au $\mathrm{IV}^{\mathrm{e}} \mathrm{s}$. Les céramiques étudiées ici proviennent du niveau claudien.

$\mathbf{n}^{0} 1$ : assiette tournée en terra nigra; lèvre arrondie; partie supérieure oblique; partie inférieure anguleuse ; pied petit, droit, fond creusé, intérieur mouluré ; couleur grise (7,5 YR N 3/), pâte grise à dégraissant sableux, bien cuite. Estampille radiale ACUTUS.

Ce type est connu avec la même signature à Nimègue (type 77 a) en Angleterre à Colchester, en Champagne à Courmelois.

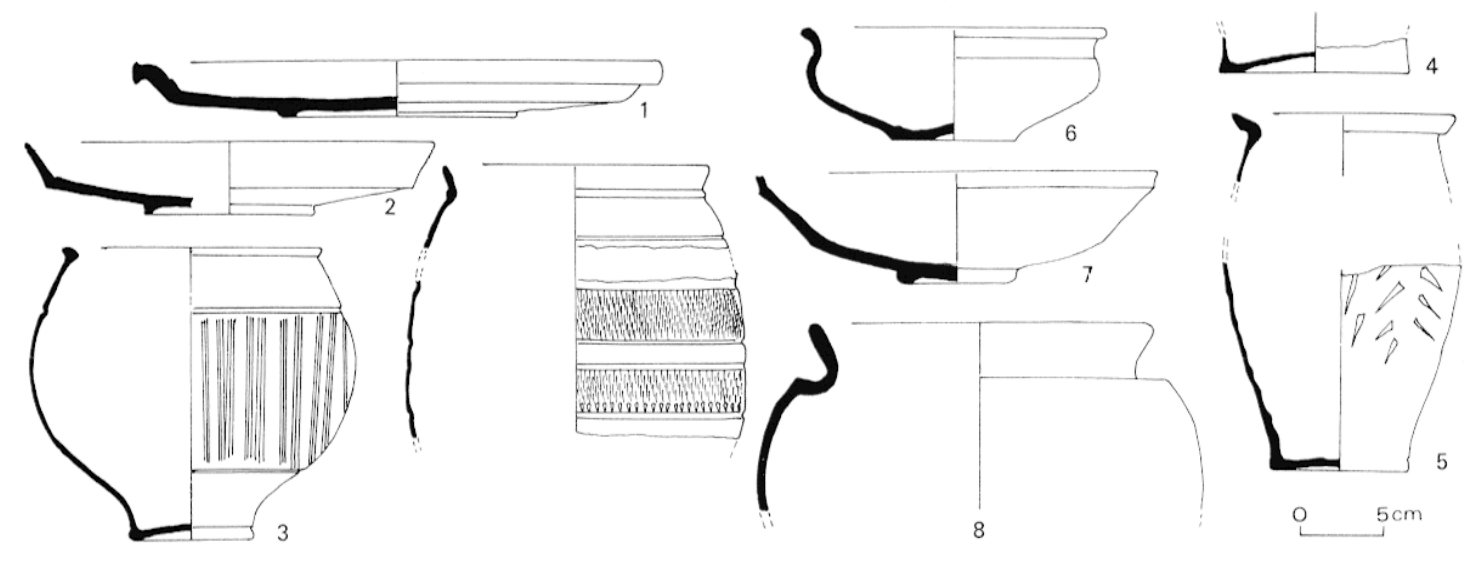

9 Mobilier de la fonille de Hamblain-les-Prés.

$\mathbf{n}^{0} 2$ : assiette tournée en terra nigra; lèvre oblique; corps caréné ; pied droit, légèrement mouluré ; fond creusé ; couleur noire $(2,5 \mathrm{YR} \mathrm{N} 3 /)$; pâte grise à dégraissant sableux, bien cuite. Type connu à Nimègue (Auguste-Tibère), à Vimy et à Sept-Saulx (fin de l'époque tibérienne) où il est associé comme ici à un vase à décor à aiguilles.

$\mathbf{n}^{0} 3$ : vase tourné en terra rubra ; lèvre aplatie ; panse ronde cannelée aux deux extrémités ; pied oblique ; fond concave ; couleur orange (2,5 YR 6/2); pâte orange à dégraissant sableux, bien cuite. La panse est ornée de bandes peignées verticales parallèles.

Type connu à Nimègue (Holwerda 29) et à Reims.

no $^{0}$ : vase tourné à enduit rouge ; lèvre oblique, suivie d'une moulure ; panse ovoïde moulurée ; fond creusé ; couleur beige ; enduit rouge (10 R 4/8). La panse est ornée de guillochis et d'excisions. Type connu à Nimègue (Holwerda 51-52), en Rhénanie (Gose 340).

$\mathbf{n}^{\circ} 5$ : vase tourné ; lèvre oblique, panse ovoïde ; petit pied oblique, précédé par une rainure ; fond creusé ; couleur blanche (10 YR 8/2); pâte blanche à dégraissant sableux, bien cuite. La panse est décorée d'aiguilles en relief.

Type connu à Nimègue (Auguste-Tibère) à Haltern, à Vimy ( $\left.\mathrm{n}^{0} 13\right)$.

$\mathbf{n}^{0} 6$ : bol tourné ; lèvre ronde; col concave; panse carénée; fond creusé ; couleur noire (5 YR 2,5/1); pâte gris foncé à dégraissant sableux, bien cuite.

Type XII a des bols carénés. 
$n^{0}$ y : bol tourné ; lèvre cannelée au sommet; corps caréné ; pied arrondi ; fond renflé au centre ; couleur noire (5 YR 3/1) ; pâte noire à dégraissant sableux, bien cuite.

Type de tradition gauloise.

$n^{0} 8$ : vase non tourné ; lèvre épaisse, anguleuse ; col concave ; panse ronde, carénée; couleur noire (5 YR 3/1); pâte grise à dégraissant sableux, bien cuite. Le haut de la panse est orné de dépressions ovalaires.

Type connu à Noyelles-Godault (Auguste-Tibère).

Foncquevillers (fig. 10). - Ce sauvetage effectué en 1978 a permis d'observer un habitat gallo-romain daté de la fin du $\mathrm{r}^{\mathrm{er}} \mathrm{s}$.

$n^{0} 1$ : assiette tournée; rebord large; lèvre en crochet; partie supérieure concave ; partie inférieure carénée ; pied oblique ; fond creusé, orné d'un anneau saillant ; couleur grise (10 YR 6/1); pâte grise à dégraissant sableux. L'intérieur est décoré d'un cercle guilloché.

Type connu à la Calotterie (fin du ier siècle).

$\mathbf{n}^{\circ} 2$ : assiette tournée ; lèvre rentrante ; partie supérieure oblique, incurvée ; partie inférieure carénée ; petit pied rond ; couleur gris clair (10 YR 6/1); pâte grise à dégraissant sableux, bien cuite. Type II a des assiettes à panse carénée, courant à Arras, Lewarde à partir de la deuxième moitié du Ier $^{\text {S. }}$

no 3 : bol non tourné ; lèvre épaisse, anguleuse ; panse ronde ; couleur gris foncé (2,5 YR N 3/); pâte grise à dégraissant fait de gravier, bien cuite.

Type de tradition gauloise.

n $^{0} 4$ : bol tourné ; lèvre ronde; col concave; mouluré ; panse carénée couleur gris claair (7,5 YR N 6/); pâte grise à dégraissant sableux bien cuite.

'Type XVI d des bols carénés, présent à Vaulx-Vraucourt.

$\mathbf{n}^{0} 5$ : bol tourné ; lèvre allongée, arrondie; col droit; panse carénée; couleur gris clair (7,5 YR N 6/) ; pâte grise à dégraissant sableux, bien cuite. Le col est orné de bandes lissées parallèles. T'ype XIV a des bols carénés, connu à Marly ${ }^{17}$, Lewarde ${ }^{18}$, très répandu dans le Nord de la France.

$n^{\circ} 6$ : bol non tourné ; lèvre aplatie, anguleuse ; col concave ; panse carénée ; couleur gris foncé (2,5 YR N3/); pâte grise à dégraissant sableux, bien cuite. Le haut de la panse est orné d'incisions allongées.

Type de tradition gauloise, connu à Lewarde (Auguste-Tibère) à Seclin (période augustéenne) ${ }^{19}$.

$\mathrm{n}^{\circ} \mathrm{y}$ : marmite tournée; lèvre allongée se terminant en crochet; panse aplatie ; couleur gris clair (10 YR 6/1) ; pâte grise à dégraissant sableux, bien cuite. La panse est ornée de bandes lissées entrecroisées.

Type I a des marmites à panse aplatie, très connu dans le Nord de la France.

17 Marie Tufrriau-Linre, Le dépoloir gallo-romain de Marly (Nord), dans Gallia, 36, 1978, pp. 163-186, 12 fig.

18 J. Demolon, Marie Tuffreau-Libre et A. Vadet, Le sile gallo-romain des lerres-noires à Lewarde (Nord), dans Revue du Nord, LXI, 1979, pp. 873-922, 22 fig.

19 S. Revillon et Marie Tufrreau-Libre, Le sile gallo-romain précoce des Tamaris à Seclin (Nord), dans Revue du Nord, 1985 

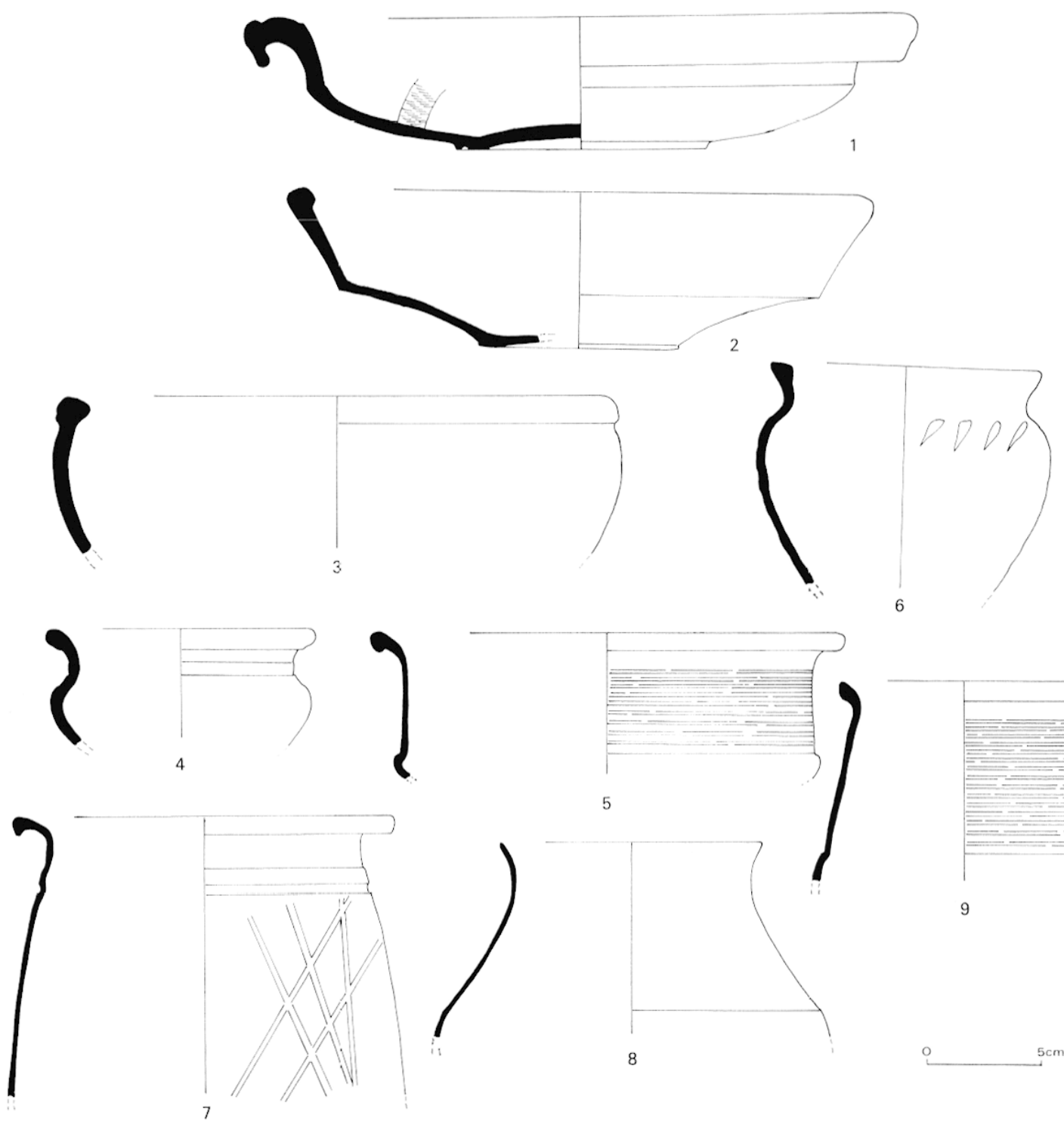

10 Mobilier de la fouille de Foncquevillers.

no 8 : vase tourné en terra nigra ; lèvre fine, prolongée par un long col ; panse carénée ; couleur gris foncé (2,5 YR N 3); pâte grise à dégraissant sableux, bien cuite.

no 9 : vase tourné ; lèvre arrondie ; col tronconique ; panse ronde, couleur gris bleu (10 YR 5/1); pâte grise à dégraissant sableux, bien cuite. Le col est orné de bandes lissées parallèles.

Type II a des vases tronconiques, connu à Vaulx-Vraucourt (n⿳012).

Arras, rue Notre-Dame de Lorelle (fig. 11). - Ce site remonte à l'époque augustéenne ${ }^{20}$.

20 A. Jacques, Fouilles gallo-romaines el médiévales à Arras 1982, bilan provisoire, dans Revue du Nord, LXV, 1983, pp. 17-29, 6 fig. 
138

MARIE TUFFREAU-LIBRE ET ALAIN JAGQUES
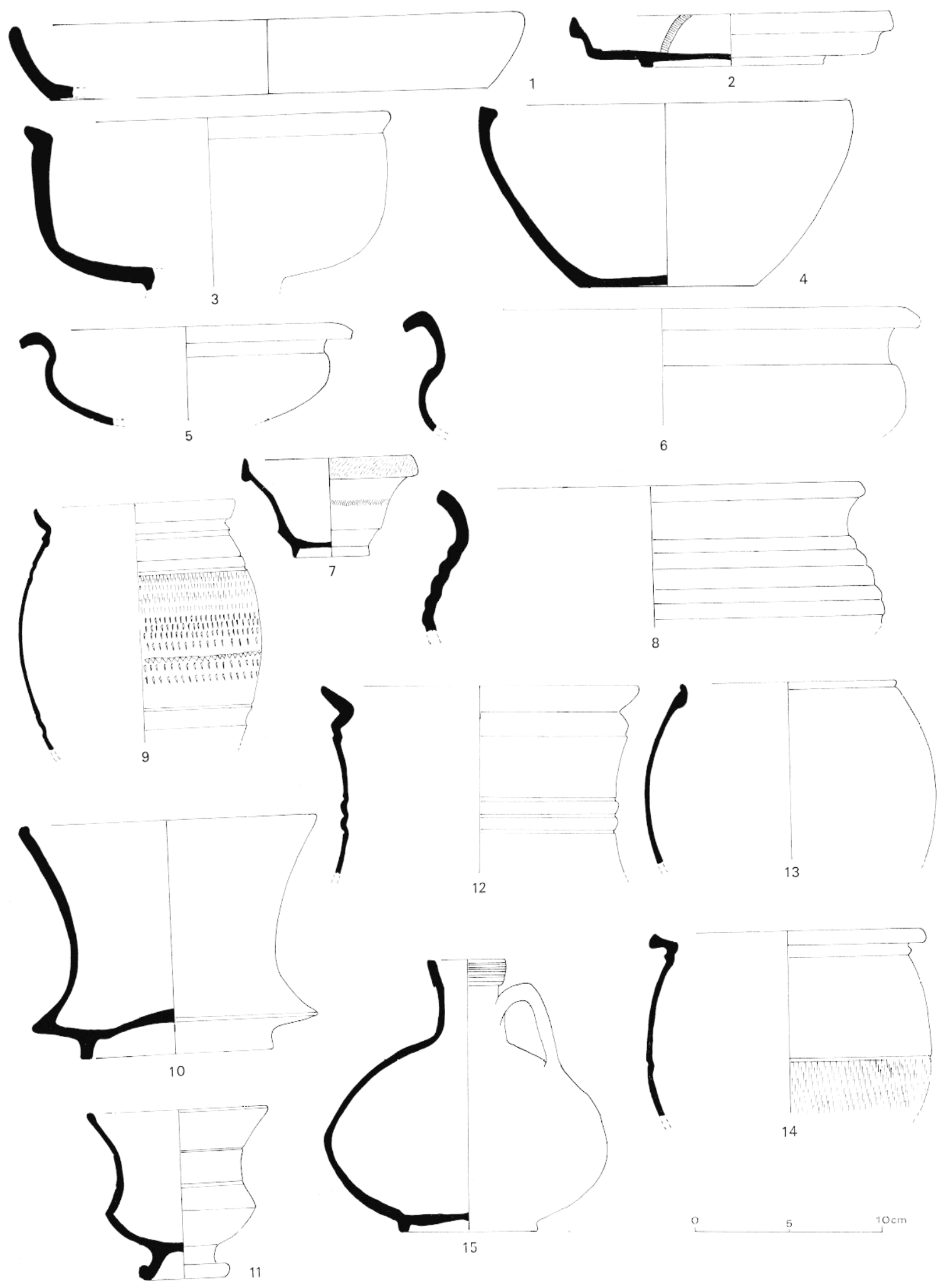

11 Mobilier de la fouille de la rue N.-L. de Lorette à Arras. 
Une aire de travail succède à un bâtiment en bois. Cet atelier a fourni le mobilier suivant, daté de la période Auguste-'Tibère.

$\mathbf{n}^{0} 1$ : assiette tournée à enduit rouge; lèvre arrondie ; corps oblique ; fond creusé ; couleur orange ; enduit rouge (10 R 4/6); pâte orange à dégraissant sableux, bien cuite.

'Type Gose 244 (époque claudienne).

$\mathbf{n}^{\circ} 2$ : assiette tournée en terra nigra ; lèvre haute ; corps anguleux ; pied oblique, mouluré ; couleur gris foncé $(2,5 \mathrm{YR} \mathrm{N} \mathrm{4/)}$; pâte gris clair à dégraissant sableux, bien cuite. L'intérieur est décoré d'un cercle guilloché.

Il s'agit d'un type proche de Gose 296 ('Tibère-Clande).

no 3 : bol non tourné; lèvre épaisse, arrondie à l'extrémité; panse ronde ; couleur grise (7,5 YR N 4/N 3/); pâte grise à dégraissant sableux, bien cuite.

no 4 : bol non tourné ; lìvre aplatie au sommet; panse ronde; couleur grise (7,5 YR N 3/) ; pâte grise à dégraissant sableux, bien cuite.

Type identique connu à Villeneuve-Saint-Germain et à Vaulx-Vraucourt.

no 5 : bol tourné ; lèvre recourbée ; col concave ; panse carénée ; couleur gris foncé (5 YR 4/1); pâte grise à dégraissant sableux, bien cuite.

Type XVI b des bols carénés, connu à Noyelles-Godault (Auguste-Tibère).

no 6 : bol tourné; lèvre recourbée; col concave; panse carénée; couleur gris foncé (2,5 YR N 3/) ; pâte grise à dégraissant sableux, bien cuite.

$\mathrm{n}^{0} 7$ : bol en terra nigra ; lèvre droite ; col concave, long ; panse carénée ; pied oblique ; fond creusé ; couleur noire. La lèvre et le col sont décorés de gruillochis.

Type $56 \mathrm{C}$ de Gamulodunum (période IV-VI).

$\mathbf{n}^{0} 8$ : bol tourné; lèvre épaisse; col oblique mouluré; panse carénée; couleur grise (10 YR 4/1); pâte grise à dégraissant sableux, bien cuile.

Type VII b des hols carénés, connu à Villeneuve-Saint-(Germain, Seclin, à Noyelles-Godault.

no 9 : vase tourné en terra rubra ; lèvre haute, arrondie à l'extérieur, incurvée à l'intérieur ; panse ovoïde moulurée ; couleur brunâtre $(2,5$ YR 5/2); pâte grise au centre, beige sur les bords. La panse est ornée de guillochis.

Type IV a des vases ovoïdes, connu à Bavay ${ }^{21}$, à Nimègue (Holwerda 51-52), à Haltern, en Rhénanie (Gose 340), en Belgique à Sampont ${ }^{21}$.

$\mathrm{n}^{0} 10$ : vase tourné en terra nigra; lèvre arrondie ; col concave, très haut; panse carénée ; pied oblique ; fond creusé ; couleur noire.

Type Gose 311 (époque augustéenne).

n $^{0} 11$ : vase en terra rubra ; lèvre renflée ; col concave, mouluré ; panse carénée ; pied concave se terminant en anneau.

no $^{\circ} 12$ : vase tourné en terra rubra ; lèvre oblique; col concave mouluré ; couleur brun orange $(2,5$ YR 4/2, 2,5 YR 5/8); pâte orange à dégraissant sableux, bien cuite.

T'ype II d des vases carénés, connu à Noyelles-Godault (Auguste-Tibère) et à Nimègue (Holwł rda 35).

21 J. Nö̈r., La nécropole yallo-romaine de IIunenkinepchen à Sampont, dans Archéologia Belgica, 106, 1968, 123 fig., 71 fig., pl. 11 h.-t. 


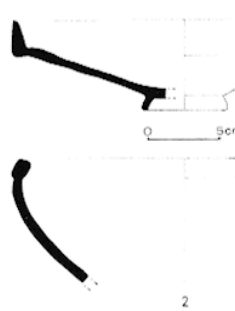

12 Mobilier de la fouille de Bonsecours à Arras.

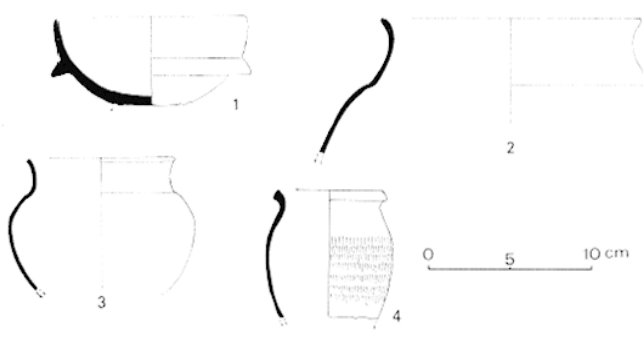

13 Mobilier de la fouille de Baudimont à Arras.

$\mathbf{n}^{0} 13$ : vase tourné à enduit rouge; petite lèvre suivie d'une panse ovoïde; couleur orange (10 R 4/8) ; enduit rouge ; pâte noire au centre, orange sur les bords, bien cuite.

$\mathbf{n}^{\circ} 14$ : vase tourné à enduit rouge ; lèvre allongée, arrondie à l'extérieur, déprimée au sommet ; panse ovoïde moulurée ; couleur rouge (2,5 YR $3 / 6)$; pâte grise à dégraissant sableux, bien cuite.

$\mathbf{n}^{0} 15$ : cruche tournée ; lèvre oblique, haute; col oblique ; panse large ; pied petit, oblique ; fond creusé ; couleur jaune.

Arras, clinique Bonsecours (fig. 12). - Les structures fouillées à la clinique Bonsecours et au carrefour de Baudimont sont des fossés datant du début du $\mathrm{I}^{\mathrm{er}} \mathrm{s}$. (Auguste-Tibère). Le mobilier recueilli est identique à celui trouvé rue Notre-Dame de Lorette. Nous les avons présentés pour montrer l'uniformité du mobilier à cette époque dans la ville romaine.

no 1 : assiette tournée en terra nigra; lèvre épaisse, prolongée par une partie supérieure droite ; partie inférieure anguleuse ; pied oblique ; fond creusé ; couleur gris foncé $(2,5 \mathrm{YR} \mathrm{N} 4 / \mathrm{N} 3 /)$; pâte grise à dégraissant sableux, bien cuite.

Type III b des assiettes carénées, connu à Noyelles-Godault.

n 2 : bol non tourné ; lèvre épaisse, anguleuse ; panse ronde; couleur gris clair (10 R 4/1); pâte grise à dégraissant sableux, bien cuite.

$\mathbf{n}^{\circ} 3$ : bol non tourné; lèvre ronde; col concave; panse carénée, moulurée; couleur grise (2,5 YR N 4/N 3/); pâte grise à dégraissant sableux, bien cuite.

no 4 : bol tourné ; lèvre oblique; col concave se terminant en corniche; panse ronde; couleur grise $(2,5$ YR N 4/); pâte grise à dégraissant sableux, bien cuite. Le haut de la panse est orné d'incisions ovalaires.

Type VI a des vases à panse ronde, connu à Noyelles-Godault.

Arras, carrefour de Baudimont (fig. 13).

$\mathrm{n}^{0} 1$ : bol tourné en terra nigra; lèvre fine; panse ronde, ornée d'une collerette; pied brisé ; couleur noire (7,5 YR N 5/); pâte grise à dégraissant sableux, bien cuite.

Type I a des bols à collerette, connu à Noyelles-Godault et à Vaulx-Vraucourt.

$\mathbf{n}^{\circ} 2$ : vase tourné ; lèvre fine arrondie ; col concave ; panse ronde ; couleur noire $(7,5$ YR N 3 l); pâte grise à dégraissant sableux, bien cuite.

$\mathrm{n}^{\circ} 3$ : vase tourné en terra nigra; lèvre fine, arrondie; col concave; panse ronde; couleur noire $(7,5$ YR N 3/); pâte grise à dégraissant sableux, bien cuite.

$n^{0} 4$ : vase tourné ; lèvre arrondie, en léger crochet; col concave; panse ovoïde; couleur orange (5 YR 7/3); pâte orange à dégraissant sableux, bien cuite. La panse est ornée de guillochis. 


\section{II. ÉTUDE GENERALE.}

De la céramique gauloise à la céramique gallo-romaine. - Au cours du $\mathrm{I}^{\mathrm{er}} \mathrm{s}$., la céramique est passée d'un répertoire purement gaulois à une céramique gallo-romaine. Le tableau suivant (fig. 14) indique les proportions de céramique fine, de céramique sigillée, de céramique ordinaire et de céramique non tournée selon les sites (fig. 14, partie de gauche), ainsi que celles de céramiques gris foncé et gris clair (fig. 14, partie de droite). Pour la ville galloromaine d'Arras, nous n'avons utilisé que la fouille de la rue Notre-Dame de Lorette, car le mobilier des autres structures n'était pas assez abondant pour réaliser des comptages crédibles. Nous n'avons pas non plus considéré dans ce tableau le matériel de la nécropole de Vaulx-Vraucourt car l'étude exhaustive du mobilier n'est pas encore publiée. L'étude des formes et du tableau permet donc de retracer l'évolution suivante.

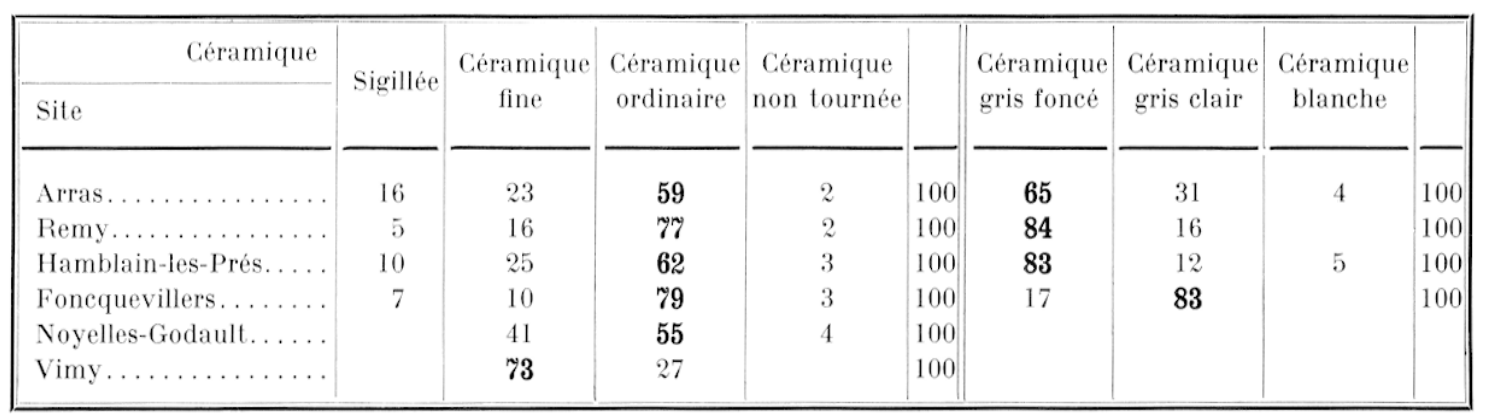

14 Pourcentages des différents types de céramiques.

Au début de la période, deux courants sont nettement distincts, que ce soit dans les campagnes (Rémy) ou dans les villes (Arras). Les céramiques ordinaires sont absolument toutes de tradition gauloise : bols à panse ronde ; bols carénés, vases à panse ronde. Aucun changement n'est enregistré dans le répertoire. La proportion des céramiques non tournées est faible ( $2 \%$ en moyenne), mais ceci semble être le cas dès le tout début de la période augustéenne (Villeneuve-Saint-Germain (Aisne), Seclin (Nord)).

A côté de ce premier courant, finalement inchangé depuis la fin de l'époque gauloise, apparait une série de fabrications fines, imitées des formes romaines, étrangères à la région : céramiques gallo-belges (terra nigra, terra rubra), céramique à enduit rouge, céramique dorée au mica. Si parfois ces objets empruntent leurs formes dans le répertoire gaulois (vases carénés, vases à piédestal, bouteille moulurée), l'ensemble est en majorité d'inspiration romaine. La sigillée est peu fréquente ( $5 \%$ à Rémy, $16 \%$ à Arras) et, par exemple, complètement absente des nécropoles. En fait, elle n'est que faiblement importée dans la région et probablement fortement concurrencée par les productions gallo-belges d'origine locale, essentiellement fabriquées en Champagne. A l'intérieur de la céramique ordinaire, le pourcentage de céramiques gris foncé traditionnelles est très élevé par rapport à la céramique gris clair encore peu courante.

A l'époque claudienne (Hamblain-les-Prés), la céramique sigillée n'est pas encore très abondante. La céramique fine a un pourcentage important et la céramique non tournée 
persiste encore. La céramique gris foncé ordinaire l'emporte toujours sur la céramique gris clair.

Ici encore deux séries de céramiques se différencient nettement : une première série de cćramiques ordinaires, tournées et, pour quelques exemplaires, non tournées, de tradition gauloise, une seconde série de céramiques fines inspirées des modèles romains. Ces séries sont absolument parallèles et n'ont pas de rapport entre elles. Il n'y a pas encore eu de contamination entre les deux. L'apport romain est important mais non assimilé, ceci au milieu du $\mathrm{I}^{\mathrm{er}} \mathrm{s}$.

Dans la nécropole de Vaulx-Vraucourt dont l'utilisation a été plus tardive (environ jusqu'aux années 80 ap. J.-C.), il faut noter l'apparition de céramiques de types nouveaux : vases carénés moins classiques, vases tronconiques, bouteilles à panse ronde d'un style nouveau. Ceci concerne seulement quelques objets car la nécropole date essentiellement de la première moitié du ${ }^{\text {er }} \mathrm{s}$., mais il est cependant visible que les céramiques sc détachent à la fois du répertoirc gaulois et des modèles italiques pour créer une garnme nouvelle qui parfois emprunte aux deux courants (vase caréné, bouteille) ou innove totalement.

Vers la fin du I $^{\text {er }}$ s., à partir du dernier quart, les différences deviennent très nettes, comme à Foncquevillers. La céramique fine voit son importance diminuer. Celle de la sigilléc reste stable. La proportion des céramiques non tournées reste identique. L'immense majorité de la céramique se constitue de céramiques ordinaires. Surtout, à l'intérieur de cette catégorie la céramique gris clair l'emporte largement sur la céramique gris foncé. Les proportions sont par exemple complètement inversées par rapport à celles de Hamblain-lesPrés, d'époque claudienne. Il subsiste quelques résidus gaulois mais la plupart des formes sont nouvelles : assiettes carénées II a (fig. $11 \mathrm{n}^{0} 2$ ) bol et vase tronconique décorés de bandes lissées (fig. 11 nos $^{\text {5-9) }}$ ) marmitc à panse aplatie I a (fig. $11 n^{0} 7$ ). De plus, l'ancien répertoire d'imitation romaine est repris de façon originale en céramique gris clair (assiette guillochée $n^{0} 1$ ). Les quelques formes en terra nigra qui subsistent ont souvent des formes nouvelles.

Les deux courants se sont donc fondus pour donner naissance à un nouveau répertoire complètement différent, contenant simplement quelques vagues réminiscences des périodes précédentes. Les deux anciens répertoires, le gaulois et le romain, vont alors disparaitre rapidement. La fabrication de la céramique fine s'arrête, à l'exception de quelques productions comme les assiettes à enduit rouge pompéien dont le succès durera jusqu'au Iv $^{e}$ s., succès probablement dû à l'adoption d'une nouvelle habitude alimentaire. Les céramiques de style gaulois disparaissent également. Par contre c'est à ce momenl que démarrent les grosses officines de la région : Labuissière, vers 90 environ ${ }^{22}$ et La Calollerie (fin du I ${ }^{\text {er }}$ s. $)^{23}$. C'est donc vers les années 80 à 90 qu'il est possible de situer la mise en place d'une nouvelle gamme de céramiques en Atrébatie bien sûr mais aussi dans les régions voisines.

22 Marie Tuffreau-Libre, Un four gallo-romain à Labuissière (Pas-de-Calais), dans Gallia, 38, 1980, pp. 291309 , fig. 15 .

23 J. Couppe, Marie Tufread-Libre el F. Vincent, L'officine gallo-romaine de La Calollerie (Pas-de-Calais), dans Revue du Nord, LIX, 1977, pp. 501-544, 22 fig. 
En ce qui concerne l'évolution de la céramique, ceci montre bien que celle-ci ne se transforme pas de facon continue. Une fois un répertoire mis en place, il peut durer très longtemps sans évoluer. Puis, en une seule fois, sous l'influence d'événements extérieurs : modes diverses, volonté d'assimilation, besoins économiques nouveaux, qui provoquent une lente maturation, ce répertoire se trouve complètement renouvelé. Cette série mise en place à la fin du i er $\mathrm{s}$. va durer au moins jusqu'à la fin du II ${ }^{\mathbf{e}} \mathrm{s}$.

Il aura donc fallu près d'un siècle pour que la céramique de tradition gauloise disparaisse et fasse place à des séries gallo-romaines. Une longue période de "digestion " des modèles romains a d'abord été nécessaire. Ceci tend à prouver que les changements politiques ne se sont répercutés que très tardivement dans la vie quotidienne. On assiste certes à une arrivée massive de céramique de style italien mais ceci concerne surtout les couches aisées de la population. La romanisation semble en fait assez faible. Si l'encadrement militaire, économique, fiscal et politique est désormais romain, les couches massives de la population sont fort peu affectées par ce nouvel état des choses. Les traditions et les habitudes de vie restent les mêmes. Au moins jusqu'à la fin du I ${ }^{\text {er }}$ s., la vie quotidienne reste gauloise.

La céramique comparée des nécropoles, des villes et des campagnes. - Il nous a été possible de mettre en lumière des faits souvent déjà suggérés, à savoir que la céramique n'est pas strictement la même dans les villes, les campagnes et les nécropoles. Les associations d'objets y sont différentes. Tout ceci reflète, de façon parfois floue, mais néanmoins significative, des aspects divers de la vie quotidienne gallo-romaine.

Nécropoles et habitats. - Les nécropoles de Noyelles-Godault et de Vimy, datées de la période Auguste-Claude ne comprennent aucune céramique sigillée. Le mobilier est composé de céramiques ordinaires de tradition gauloise et de céramiques fines d'imitation romaine. Cette absence totale de céramiques sigillée est à souligner. Dans les habitats contemporains : Arras, Rémy, Hamblain-les-Prés, donc que ce soient des structures de villes ou de campagnes, la céramique sigillée existe dès la fin de la période augustéenne. Par contre, elle n'apparait dans les nécropoles qu'après l'époque claudienne. Dans la nécropole de Sampont par exemple, essentiellement d'époque Auguste-Claude, mais qui se prolonge jusqu'au $\mathrm{II}^{\mathrm{e}} \mathrm{s}$., seules quelques tombes du troisième quart du $\mathrm{I}^{\mathrm{er}} \mathrm{s}$. et du début du ${ }_{\mathrm{II}^{\mathrm{e}}}{ }^{\mathrm{s}} \mathrm{s}$. ont des céramiques sigillée, encore que très peu nombreuses.

A Vaulx-Vraucourt, la nécropole semble avoir été utilisée de la période augustéenne jusqu'au dernier quart du I $^{\text {er }} \mathrm{s}$. Elle ne contient pas de sigillée, à l'exception d'un seul exemplaire réparé anciennement avec des agrafes en fer, traitement réservé aux objets précieux. Ceci met en évidence la rareté des céramiques sigillée en Atrébatie, jusqu'à la fin du ${ }^{\text {er }}$ s. mais pose aussi un autre problème. Cette absence de céramique sigillée dans les nécropoles et non dans les habitats même campagnards, s'explique-t-elle seulement par la rareté de cette céramique ou faut-il y voir le reflet de coutumes et le refus de mettre dans des sépultures des objets qui ne sont ni traditionnels, ni d'origine régionale.

L'essentiel du mobilier de ces tombes est constitué de céramiques fines d'imitation romaine, mais de fabrication régionale (gallo-belge, céramique dorée, $41 \%$ à NoyellesGodault, $73 \%$ à Vimy) (fig. 14). Ces proportions sont beaucoup plus faibles en ville (23\%) 
et en campagne (16\%). Les fréquences des céramiques sont complètement inversées entre les deux types de structure, ce qui s'explique évidemment par la volonté de déposer dans les tombes le plus beau mobilier que la famille possède ou qu'cllc achète à cette occasion. L'importance des céramiques fines est d'ailleurs proportionnelle à la richesse de la nécropole.

Nécropoles riches et nécropoles pauvres. - La comparaison entre les nécropoles de Vimy et de Noyelles-Godault met en évidence certains éléments. Les tombes de Vimy sont au nombre de 10 et comprennent 103 céramiques. Cinq de ces tombes contiennent un service à libation (fig. $4 \mathrm{n}^{\text {os }} 9$-10) et regroupent à elles seules 76 céramiques. La moins riche des sépultures comprend 13 céramiques, la plus riche 18. Le mobilier funéraire est également composé d'un miroir et de fibules pour trois d'entre elles, d'un couteau pour quatre d'entre elles, d'un trépied et d'un rasoir dans une seulement. Les cinq autres tombes sont moins importantes (6 à 8 céramiques) mais incluent également pour certaines des fibules, un miroir, un couteau, une verrerie. Le mobilier se compose de productions en terra nigra, en terra rubra, céramique dorée, céramique à enduit rouge $(73 \%)$. Il y a peu de céramiques ordinaires $(27 \%)$ (fig. 14).

Par contre, la nécropole de Noyelles-Godault, contemporaine est plus pauvre. Les tombes les plus riches comprennent de 6 à 12 céramiques. Il y a quelques fibules, mais aucun miroir et pas d'autres objets comme les couteaux, rasoir, trépied de Vimy. Le mobilier se compose ici encore de céramiques fines (terra rubra, terra nigra, céramique à enduit rouge : $41 \%$ ), mais les vases en pâte ordinaire sont beaucoup plus nombreux (59\%) les proportions sont donc inversées par rapport à celles de Vimy. Beaucoup de tombes ne contiennent qu'une ou deux céramiques. Certaines n'ont aucun mobilier. La moyenne par tombe est de 3,80 au lieu de 10,3 à Vimy. Les sépultures de Vimy sont isolées mais il est probable qu'elles dépendaient d'une villa proche.

Selon A. Van Doorselaer, il existerait deux cimetières pour chaque villa, l'un peu étendu mais renfermant des tombes au riche mobilier, réservé au propriétaire et à sa famille, l'autre destiné au personnel d'exploitation, plus étendu mais plus pauvre. Les tombes de Vimy appartiennent à la première catégorie ; la nécropole de Noyelles-Godault à la seconde. Il existe donc, à cette période (Auguste-Claude) une différence entre riches et pauvres, visible au niveau des dépôts dans les sépultures. La proportion de céramiques fines, le nombre total des objets portés dans la tombe sont immédiatement fonction du niveau social du défunt. Les objets rares dans la vie courante $(10$ à $25 \%$ de céramiques fines dans les habitats) sont conservés pour être déposés en nombre dans les sépultures. Celles-ci sont plus fréquentes lorsque les défunts sont des notables, ce qui, ici encore, peut être simplement dû à des différences de richesse mais aussi d'assimilation. Les cadres ont pu adopter plus vite les objets d'imitation romaine.

Villes et campagnes. - En milieu urbain (Arras), la céramique fine est de $23 \%$ durant la période Auguste-Tibère. Elle n'est que de $16 \%$ en campagne. A l'époque claudienne, cette même céramique atteint dans les campagnes la même proportion que dans les villes pendant la période précédente ( $25 \%$ à Hamblain-les-Prés). Les campagnes ont donc un léger retard par rapport aux villes, ce que viennent confirmer les proportions comparées des céramiques gris clair et gris foncé. I a céramique gris foncé est de $65 \%$ en milieu urbain 
contre $84 \%$ à la campagne, ceci jusqu'à l'époque claudienne ( $83 \%$ à Hamblain-les-Prés) (fig. 14). Enfin, la céramique sigillée est plus abondante dans les villes qu'en campagne, toutes époques confondues.

L'abandon de la céramique de tradition gauloise et l'arrivée du nouveau répertoire réalisé en pâte gris clair sont donc plus rapides dans les villes. Le décalage entre les deux peut aller de 15 à 20 ans.

La céramique du Sud de l'Atrébatie reste donc traditionnelle jusqu'au troisième quart du I $^{\text {er }}$ s. L'apport romain semble plaqué sur une réalité quotidienne inchangée. Une fois de plus, l'étude de la céramique est significative. Il faut ici souligner deux aspects du problème. Il est apparu plus haut qu'un répertoire de céramiques pouvait durer très longtemps. En tant qu'élément de datation, la céramique doit donc être utilisée avec discernement. Un objet isolé ne peut donner un indice chronologique très précis. Par contre, les différences d'organisation d'ensembles de céraniques ou de proportion des différents types peuvent donner des datations suggestives.

D'autre part, l'intérêt de cette céramique est surtout de refléter la vie quotidienne gallo-romaine. Elle est beaucoup plus proche de la réalité vécue des populations que bien des objets prestigieux qui peuvent n'offrir qu'un aspect superficiel et parfois artificiel de la question.

\section{Marie Tuffreau-Libre* ${ }^{*}$ et Alain JAcQues} ${ }^{\star}$ C.N.R.S. 